\title{
Diagnosis and Management of Hepatitis B and Hepatitis C Infections in Children
}

\author{
Malathi Sathiyasekaran¹, Ganesh Ramaswamy²
}

\begin{abstract}
The hepatitis B virus (HBV) and hepatitis C virus (HCV) in most children remain asymptomatic, but have the potential to progress to chronic hepatitis, cirrhosis, end-stage liver disease, and hepatocellular carcinoma. Vertical transmission is a unique feature seen with both these viruses and plays an important role in the natural history and management. Since prevention is better than cure, every effort should be made to prevent these diseases as significant transmission occurs during the perinatal period. Therefore, it is very essential that all pediatricians/ gastroenterologists treating children with $\mathrm{HBV}$ and $\mathrm{HCV}$ infections be aware of the details relating to the viruses before considering therapy.

Keywords: Children, Hepatitis B, Hepatitis C.

Pediatric Infectious Disease (2020): 10.5005/jp-journals-10081-1238
\end{abstract}

\section{INTRODUCTION}

Viral infections due to the two hepatotrophic viruses, hepatitis B virus (HBV) and hepatitis C virus (HCV), are distributed globally. In most children these infections remain asymptomatic, but have the potential to progress to chronic hepatitis, cirrhosis, end-stage liver disease, and hepatocellular carcinoma. Vertical transmission is a unique feature seen with both these viruses and plays an important role in the natural history and management. Though these two viruses seem to share some similarities, there are some salient differences in the viral characteristics, natural history, management, and prognosis. At present, the goal of treatment in HBV infection is to achieve a functional cure since absolute or virological cure is difficult. However, in HCV, a complete eradication is possible with the availability of newer direct-acting antiviral agents. Since prevention is better than cure, every effort should be made to prevent these diseases as significant transmission occurs during the perinatal period. Therefore, it is very essential that all pediatricians/ gastroenterologists treating children with $\mathrm{HBV}$ and $\mathrm{HCV}$ infections be aware of the details relating to the viruses before considering therapy.

\section{Epidemiology of HBV and HCV}

These infections occur worldwide and are seen in all age-groups. According to $\mathrm{WHO}$, an estimated $2 \%$ of the general population is infected with HBV in Southeast Asia. ${ }^{1}$ The prevalence of HBV in India in the non-tribal populations is $2.4 \%$, and among tribal populations, it is $15.9 \%$. $^{2}$ The incidence of HBV has decreased globally because of the universal immunization programs and screening of blood donors and high-risk personnel.

The global prevalence of HCV is estimated at $2.5 \%$ with a viremic rate of $67 \%,{ }^{3}$ whereas in India it ranges from 1 to $1.9 \%{ }^{4}$ The prevalence of $\mathrm{HCV}$ infection in children varies from $0.05 \%$ to $0.36 \%$ in the USA and Europe and from 1.8\% to 5.8\% in some developing countries. ${ }^{5}$ In Punjab and Northeast India, a high anti-HCV positive rate due to the reuse of needles and syringes had been reported. ${ }^{6}$

\section{Viral Characteristics}

Hepatitis B virus is a $42 \mathrm{~nm}$ complex, incomplete double-stranded DNA virus. It is highly contagious, and $0.0002 \mathrm{~mL}$ of infected blood
${ }^{1}$ Department of Pediatric Gastroenterology, Rainbow Children's Hospital, Chennai, Tamil Nadu, India

${ }^{2}$ Department of Pediatrics and Metabolic Disorders, Rainbow Children's Hospital, Chennai, Tamil Nadu, India

Corresponding Author: Malathi Sathiyasekaran, Department of Pediatric Gastroenterology, Rainbow Children's Hospital, Chennai, Tamil Nadu, India, Phone: +919841041991, e-mail: mal.bwcs@gmail. com

How to cite this article: Sathiyasekaran M, Ramaswamy G. Diagnosis and Management of Hepatitis B and Hepatitis C Infections in Children. Pediatr Inf Dis 2020;2(1):12-18.

Source of support: Nil

Conflict of interest: None

is sufficient to spread the infection. The biomarkers related to $\mathrm{HBV}$ are hepatitis surface antigen $(\mathrm{HBsAg})$, core antigen $(\mathrm{HBcAg})$, envelope antigen $(\mathrm{HBeAg})$, and the corresponding antibodies anti-HBs, anti-HBc (IgG, IgM) and anti-HBe. The HBV genome is a circular, partially double stranded DNA. HBV DNA in the blood is a marker of viremia and infectivity. The quantification of DNA is essential to decide on therapy. The significance of these biomarkers is shown in Table 1. There are more than 10 HBV genotypes which may differ in severity of presentation and response to therapy. The genotypes $A$ and $D$ are common in India. During the entry into the hepatocyte, the HBV integrates into the host nucleus and forms the covalently closed circular DNA which is the basis for the complexity in the eradication of the virus.

Hepatitis $C$ virus belongs to the Flaviviridae family and is a 30-80 nm RNA virus which is less infective but more sinister compared to HBV. The two biomarkers of HCV, viz. anti-HCV antibody and HCV RNA, are helpful in establishing the diagnosis. There are six genotypes of HCV which may predict the response to therapy. In India, the principal genotypes are genotype 3 followed by genotype 1 . In the hepatocyte, HCV remains as an intracytoplasmic virus and does not integrate into host nucleus like HBV and, therefore, it is possible to cure a person with HCV infection. 
Hepatitis B and Hepatitis C Infections in Children

Table 1: Biomarkers of HBV and their significance

\begin{tabular}{|c|c|c|c|}
\hline Antigen (Ag) & Significance & Corresponding $A b$ & Significance \\
\hline \multirow[t]{2}{*}{ HBsAg (surface Ag) } & Present in acute and chronic infection & Anti-HBs & Protective antibody \\
\hline & Simple screening test & & $\begin{array}{l}\text { Seen following natural infection and effective } \\
\text { immunization }\end{array}$ \\
\hline \multirow[t]{2}{*}{ HBeAg (envelope Ag) } & Indicates infectivity & Anti-HBe & $\begin{array}{l}\text { Marker for good response to treatment of } \\
\text { HBeAg-positive CHB }\end{array}$ \\
\hline & Present in acute and chronic stages & & Not a protective $A b$ \\
\hline \multirow[t]{2}{*}{$\mathrm{HBcAg}$ (core Ag) } & Not seen in blood & Anti-HBc IgM & Recent infection \\
\hline & Present in hepatocytes & Anti-HBc lgG & Past infection \\
\hline
\end{tabular}

HBV DNA reflects viral replication; the levels indicate the need and response to therapy

\section{Transmission of HBV and HCV}

These viruses are spread by either vertical or horizontal route through blood, blood products, and body fluids. Vertical transmission of HBV is significantly higher if the mother has a high viral load (HBV DNA levels) and is HBsAg and HBeAg positive. ${ }^{7}$ Mother-infant transmission of HCV during the perinatal period is common, accounting for $60 \%$ of the cases, ${ }^{5}$ and the risk increases with concomitant human immunodeficiency virus infection, high maternal HCV viral load, and extended exposure to maternal blood (fetal pH monitoring, prolonged rupture of membranes, etc.). Those requiring repeated blood transfusions and IV drug abusers are also prone to HCV infection.

\section{Natural History of HBV and HCV INFECTIONS}

When a child acquires HBV infection, majority will clear the virus and seroconvert naturally. The proportion of children with higher seroconversion are those who are older and are icteric. It is evident that $90 \%$ of infants born to mothers who are highly infectious (HBsAg and $\mathrm{HBeAg}$ positive) become chronic HBV carriers compared to $30 \%$ and less than $10 \%$ of those who infected later before 5 years and 10 years of age, respectively. ${ }^{8}$ Chronic hepatitis B (CHB) may progress to cirrhosis, end-stage liver disease, hepatocellular carcinoma (HCC), and death if not treated appropriately (Flowchart 1). Liver transplantation has significantly changed the natural history of chronic HBV infection. It has been estimated that 3-5\% and $0.01-0.03 \%$ of children with chronic HBV infection develop cirrhosis or hepatocellular carcinoma (HCC), respectively, before adulthood. ${ }^{9}$

HCV infection is detected incidentally in more than $90 \%$ of individuals who are asymptomatic. HCV infection is more morbid than HBV infection and is appropriately called a silent killer. In adults, 10-15 years following infection, $54-80 \%$ will progress to chronic hepatitis with $5-10 \%$ progressing to cirrhosis and $2-5 \%$ to HCC by 40-60 years (Flowchart 1). However, in children, the natural history is different with spontaneous resolution seen in $25-40 \%$ by $2-3$ years of age and $6-12 \%$ up to 7 years of age. Majority of children (80\%) with chronic hepatitis $\mathrm{C}(\mathrm{CHC})$ do not undergo spontaneous resolution, but remain asymptomatic; $14 \%$ may present with chronic hepatitis, and $1-2 \%$ may progress to cirrhosis. ${ }^{10}$

\section{Approach to Diagnosis and Management OF HBV/HCV INFECTION}

\section{History and Examination}

A detailed history for the presence and duration of jaundice, fluid retention, altered sensorium, loss of weight or appetite, GI bleeds, urine output, and risk factors such as blood transfusions, surgery, needle pricks, IV drug use, tattoos, liver disease in the family, death related to liver disease and HCC should be elicited. A thorough clinical examination for the presence of icterus, clubbing, edema, nutritional status, palmar erythema, liver size and consistency, splenomegaly, free fluid, and the presence of abdominal veins including other systemic examinations should be recorded. Extrahepatic manifestations such as arthralgia/arthritis, vasculitis, polyarteritis nodosa, thrombocytopenia, urticarial, and glomerulonephritis should also be noted.

\section{Investigations}

Basic

Complete blood count, biochemical tests of the liver, prothrombin time, INR, serum creatinine, and blood sugar should be performed.

\section{Viral Serology}

HBV: HBsAg, IgM anti-HBc, HBeAg, anti-HBe, and HBV DNA.

HCV: anti-HCV, HCV RNA, and genotype.

\section{Imaging}

Ultrasound of abdomen and upper $\mathrm{Gl}$ endoscopy should be done when chronic $\mathrm{CHB}$ or $\mathrm{CHC}$ infection is suspected.

\section{Histopathology}

Liver biopsy is preferable prior to initiating therapy in chronic hepatitis B. This may be useful when the transaminases are normal or fluctuating and there is family history of liver disease. However, in $\mathrm{CHC}$, antiviral therapy can be started even without liver biopsy.

\section{FibroScan}

Transient elastography is a good noninvasive test to detect and grade liver fibrosis. The advantages of FibroScan are as follows: it is painless, quick ( $<5$ minutes), highly reproducible, and easy to perform in the outpatient clinic or bedside, and it may replace liver biopsy in some select situations. ${ }^{11}$

\section{THERAPY OF HBV/HCV INFECTION}

Apart from supportive therapy, the definitive therapy for HBV infection include antivirals tenofovir disoproxil fumarate (TDF) 300 $\mathrm{mg}$ in children $>12$ years of age and entecavir (ETV) in children $>2$ years of age at a dose of $0.015 \mathrm{mg} / \mathrm{kg} /$ day for children weighing $10-30 \mathrm{~kg}$ and $0.5 \mathrm{mg}$ if the weight is more than $30 \mathrm{~kg}$. These drugs have minimal side effects and least drug resistance. Interferon (IFN- $\alpha$ ) and PEGylated IFN- $\alpha$ are still recommended though they are not child-friendly, but they are the only drugs which have a 
Flowchart 1: Natural history of HBV and HCV infections

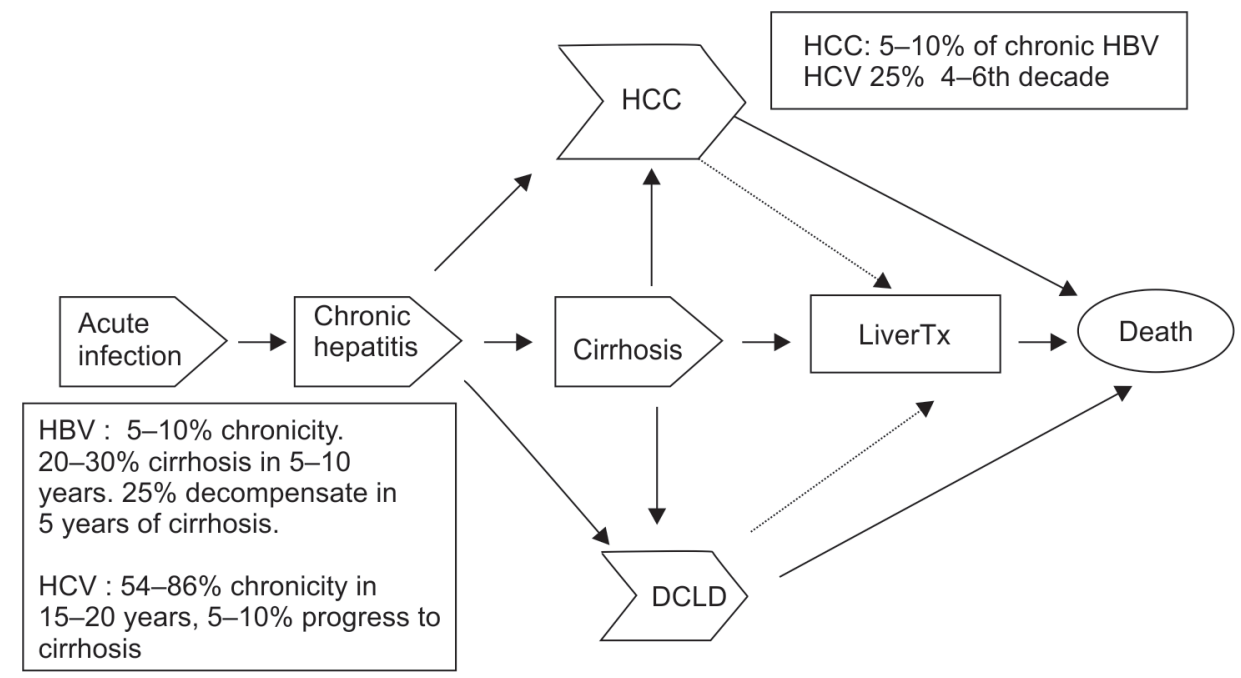

finite therapy and have been reported to help in viral clearance and formation of anti-HBs.

The drugs approved for HCV infection are PEGylated IFN and ribavirin. These drugs have several side effects, have variable response to therapy, and warrant frequent monitoring. The currently available direct-acting antivirals (DAAs) have high efficacy and are well tolerated with a short duration of treatment. These advantages seen in adult patients have been the key driver to treat children with HCV infection. DAAs target specific nonstructural proteins of $\mathrm{HCV}$ and act by disrupting viral replication and infection. They target the NS3/NS4A proteases, the NS5A proteins, and the NS5B RNA-dependent RNA polymerases. ${ }^{12}$ A well-established and well-studied fixed drug combination is sofosbuvir (polymerase inhibitor) and ledipasvir (N5SA inhibitor). ${ }^{13}$ The doses for these fixed drug combinations in children are weight dependent and are shown below:

- Weight less than $17 \mathrm{~kg}=33.75 \mathrm{mg}$ of sofosbuvir (S) and $150 \mathrm{mg}$ ledipasvir (L).

- Weight between $17-35 \mathrm{~kg}=45 \mathrm{mg}$ of $\mathrm{S}$ and $200 \mathrm{mg}$ of $\mathrm{L}$.

- Weight more than $35 \mathrm{~kg}=90 \mathrm{mg}$ of $\mathrm{S}$ and $400 \mathrm{mg}$ of $\mathrm{L}$.

Though several other pangenotypic DAAs such as velpatasvir and glecaprevir have been introduced for adults, they are not as yet approved for children. The goal of therapy in children is to cure $\mathrm{HCV}$ infection, thereby preventing the possible progression to complications. Liver transplant is the definitive treatment for those with acute liver failure and decompensated chronic liver disease not responding to antiviral therapy.

The clinical spectrum of HBV and HCV infections is discussed in detail below.

\section{Clinical Spectrum of HBV Infection}

The majority of children with HBV infection are asymptomatic and are incidentally detected to have hepatomegaly, elevated serum transaminases, or HBsAg positivity. The spectrum of symptomatic HBV infection includes acute hepatitis, acute liver failure, acute-onchronic liver failure, chronic hepatitis $\mathrm{HBeAg}$ positive or negative, cirrhosis (compensated/decompensated), end-stage liver disease, and hepatocellular carcinoma. Irrespective of whether the child is asymptomatic or symptomatic, a detailed evaluation should be done to check for liver and virological status. The diagnosis and management of the HBV infection will depend on the presentation:

\section{Acute Viral Hepatitis B: (AVH-B)}

HBV occurs in $10-15 \%$ of children with AVH in India. The majority are anicteric and may be asymptomatic. The classical symptomatic $\mathrm{AVH}-\mathrm{B}$ infection presents with a prodrome, an icteric phase, and a convalescence phase. Extrahepatic manifestations may be seen in some patients. Less than $10 \%$ of infants born to HBeAg-positive mothers develop acute hepatitis. In children more than 5 years of age with AVH-B, $90-95 \%$ will resolve, $5-10 \%$ will progress to chronic hepatitis and about $1 \%$ to ALF.

Diagnosis: Elevated serum bilirubin and transaminases (ALT, AST $>2$ ULN (upper limit of normal); may be even >20 ULN). HBsAg and anti-HBC IgM are positive, and $\mathrm{HBeAg}$ positive or negative with high HBV DNA.

Therapy: The treatment of acute HBV is mainly supportive and involves close monitoring for the features of acute liver failure, extrahepatic complications, and progression to chronic hepatitis. Those who recover should have HBsAg rechecked after 6 months-if HBsAg is negative and anti-HBs positive, the child has seroconverted. However, if $\mathrm{HBsAg}$ continues to be positive, the child has progressed to chronic hepatitis. Antivirals are recommended for acute severe hepatitis.

\section{Acute Liver Failure (ALF)}

HBV-related ALF is uncommon (1\%) in infants and children and is associated with more than $40 \%$ mortality without liver transplantation. The child with ALF usually presents with fever, abdominal pain, vomiting, jaundice, coagulopathy followed by encephalopathy.

Diagnosis: Elevated serum bilirubin and transaminases, prolonged INR $>1.5$ in the presence of encephalopathy and INR $>2$ in the absence of encephalopathy, $\mathrm{HBsAg}$ positive, $\mathrm{HBeAg}$ positive or negative, and high HBV DNA.

Therapy: Antiviral therapy with tenofovir or entecavir is recommended for severe acute hepatitis and ALF; however, IFN is 
contraindicated. The criteria for severe acute hepatitis include coagulopathy (INR 1.5) or a protracted course (i.e., persistent symptoms for more than 4 weeks or marked jaundice total bilirubin $>10 \mathrm{mg} / \mathrm{dL}$ ). Early antiviral therapy with highly potent nucleoside analogs can prevent progression to ALF, liver transplant, or death. This is not seen if therapy is initiated late in the course of severe acute hepatitis $B$ or in patients with already established acute liver failure and advanced HE. Antiviral therapy does not increase the incidence of chronicity.

\section{Acute-on-chronic Liver Failure (ACLF)}

This is an acute hepatic insult manifesting as jaundice (serum total bilirubin $>5 \mathrm{mg} / \mathrm{dL}$ ), coagulopathy (INR $>1.5$ ) complicated within 4 weeks by ascites, and encephalopathy in a child with previously diagnosed or undiagnosed HBV-related chronic liver disease/cirrhosis. It is difficult to differentiate AVH-B from ACLF unless the underlying $\mathrm{HBsAg}$ status is known, and therefore, it requires a high index of suspicion. Mutations in the HBV genome, immunosuppressive therapy, and viral or drug-induced injury are common causes of reactivation. ACLF is associated with a high mortality unless early intervention is initiated. Liver transplant is the definitive treatment for those who do not respond to standard therapy.

Diagnosis: Elevated bilirubin, prolonged INR, low serum albumin \pm elevated transaminases, $\mathrm{HBsAg}$ positive, $\mathrm{HBeAg} \pm$, anti-HBc IgM positive, and high HBV DNA. Imaging may show coarse liver echotexture with ascites. Upper GI endoscopy may show varices.

Therapy: The use of a potent oral nucleoside (nucleotide) analog early in the course of the disease, either entecavir or tenofovir, is necessary in patients with ACLF. A reduction in HBV DNA by $\geq 2$ logs from baseline after 2 weeks of tenofovir has shown to improve transplant-free survival. Liver transplantation is the definitive therapy who do not respond to antivirals.

\section{Chronic Hepatitis $B(\mathrm{CHB})$}

Children who are HBsAg positive for more than six months are termed as having chronic hepatitis B. Children with CHB may be asymptomatic or symptomatic. Chronic HBV infection is a dynamic disease and reflects the interaction between viral replication and the host-immune response. ${ }^{14}$ The phases of $\mathrm{HBV}^{15}$ are shown in Table 2. A single determination of viral markers or transaminase level may not reflect the actual phase of infection. These phases are of variable duration, may or may not be sequential, and may not be seen in all individuals with HBV infection. The old terminologies such as immune tolerant, immune-active $\mathrm{HBeAg}$-positive $\mathrm{CHB}$, immune-active $\mathrm{HBeAg}$-negative $\mathrm{CHB}$, inactive carrier, $\mathrm{HBs} \mathrm{Ag}$ clearance have been changed.

$H B V$-related cirrhosis: The diagnosis is made by the presence of the following biomarkers: $\mathrm{HBsAg}+, \mathrm{HBeAg} \pm$ with variable levels of $\mathrm{HBV}$ DNA and clinically by the presence of a firm liver, splenomegaly, free fluid, abdominal veins and imaging showing coarse echoes and varices on endoscopy. Biochemically, low serum albumin and prolonged INR are the two characteristic indices. Liver biopsy is essential to confirm diagnosis.

$H B V$-related end-stage liver disease: The pediatric end-stage liver disease (PELD) scoring is recommended for prioritizing the need for liver transplant. The indices used for scoring are age less than 1 year, albumin, bilirubin, prothrombin time, and growth failure.

HBV-related hepatocellular carcinoma (HCC): $\mathrm{HCC}$ has been described in children with both vertical and horizontal transmissions. The incidence of HCC in young patients in Taiwan has significantly decreased following universal immunization. The diagnosis of HCC is established by HBsAg positivity, high HBV DNA titers, elevated AFP, and triphasic CECT imaging showing the characteristic findings of HCC and histopathology confirming the same.

Therapy for chronic hepatitis B: Those children with either HBeAgpositive or HBeAg-negative chronic hepatitis B with persistently (minimum more than 3 months) elevated transaminases should be treated as per the present recommendations of ESPGHAN and APASL. The algorithms recommended by APASL 2015 for the management of $\mathrm{HBeAg}$-positive and $\mathrm{HBeAg}$-negative $\mathrm{CHB}$ are shown in Flowcharts 2 and 3. Since active HBV replication is the key driver of liver injury and disease progression, sustained viral suppression is of paramount importance and it is ideal to continue treatment till the occurrence of HBsAg seroconversion. Generally, in $\mathrm{HBeAg}$-positive $\mathrm{CHB}$, therapy is continued for minimum 1 year after $\mathrm{HBeAg}$ seroconversion. In $\mathrm{HBeAg}$-negative $\mathrm{CHB}$, therapy is to be continued lifelong or till HBsAg seroconversion occurs. ${ }^{16}$

\section{Chronic HBV Infection}

Immune tolerance (IT) of HBeAg-positive infection: In this phase, the transaminases are normal, but the HBV DNA is very high. At present, there is no definite treatment for this phase. The recommendation for IT-phase HBeAg-positive infection is to monitor the patient every 3 months. Liver biopsy is done if ALT is persistently elevated or there

Table 2: Phases of chronic HBV infection

\begin{tabular}{llllll}
\hline Parameter & $\begin{array}{l}\text { HBeAg positive } \\
\text { chronic infection }\end{array}$ & $\begin{array}{l}\text { HBeAg positive chronic } \\
\text { hepatitis }\end{array}$ & $\begin{array}{l}\text { HBeAg negative } \\
\text { chronic infection }\end{array}$ & $\begin{array}{l}\text { HBeAg negative } \\
\text { chronic hepatitis }\end{array}$ & HBsAg negative phase \\
\hline HBsAg & High & High/intermediate & Low & Low/intermediate & Negative anti-HBc + \\
HBeAg & Positive & Positive & Negative & Negative & Negative \\
HBV DNA & $>10^{7} \mathrm{IU} / \mathrm{mL}$ & $10^{4}-10^{7} \mathrm{IU} / \mathrm{mL}$ & $<2000 \mathrm{IU} / \mathrm{mL}^{*}$ & $>2000 \mathrm{IU} / \mathrm{mL}$ & $<10 \mathrm{IU} / \mathrm{mL}$ \\
ALT & Normal & Elevated & Normal & Elevated & Normal \\
Liver disease & None/minimal & Moderate/severe & None & Moderate/severe & Nil \\
Disease progression & Low & Moderate-high & Very low & Moderate-high & None \\
Treatment & Not indicated & Indicated & Not indicated & Indicated & Not indicated \\
Old terminology & Immune tolerant & HBeAg-positive & Inactive carrier & HBeAg-negative & HBsAg clearance/ \\
& & chronic hepatitis B & & chronic hepatitis B & occult HBV \\
\hline
\end{tabular}

**Persistently or intermittently. HBV DNA levels $>2000-20,000 \mathrm{IU} / \mathrm{mL}$ may be present without features of chronic hepatitis 
Flowchart 2: Algorithm for management of chronic hepatitis B children who are HBeAg positive (Adapted from APASL 2015 recommendations)

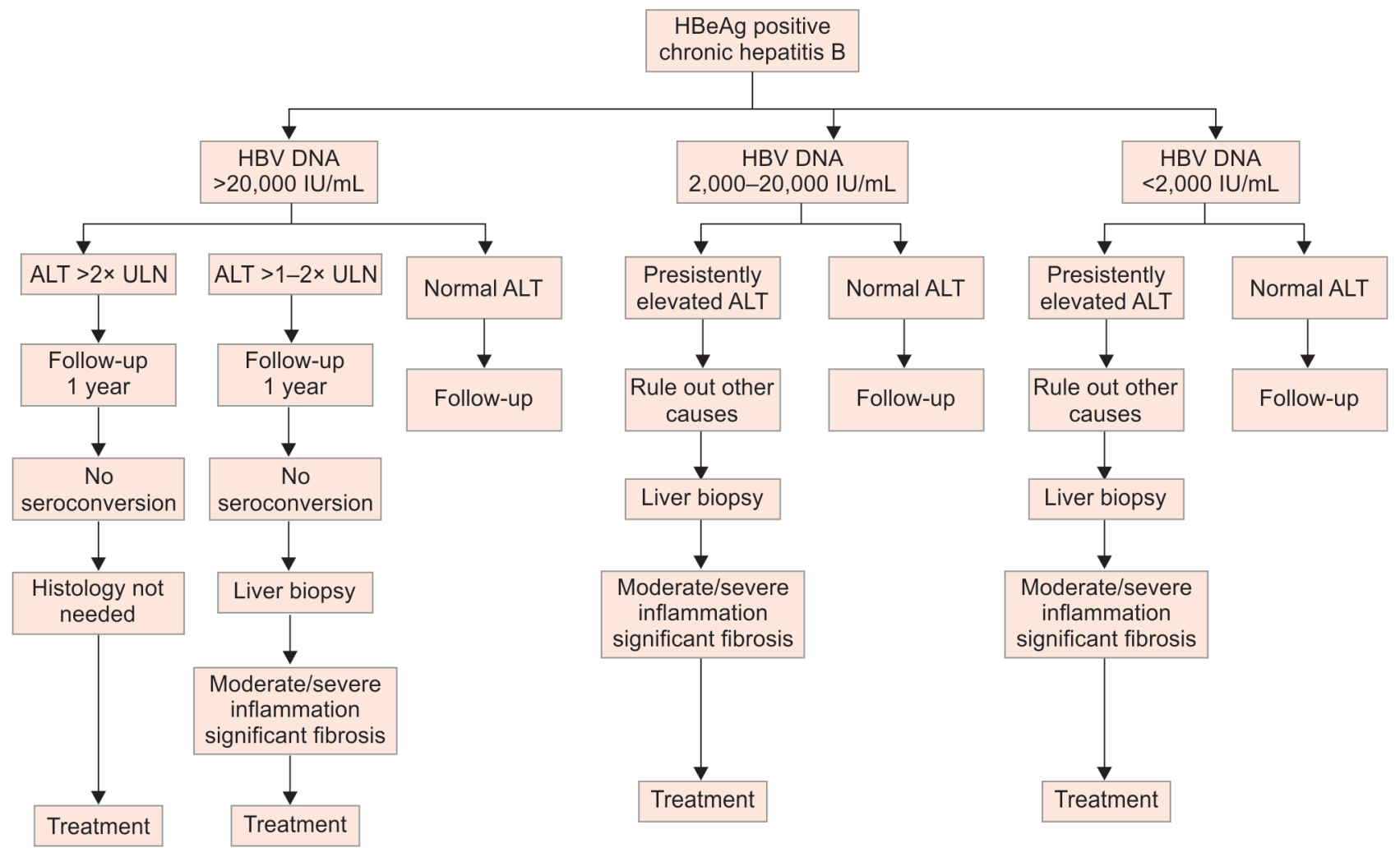

Flowchart 3: Algorithm for management of chronic hepatitis B children who are HBeAg negative (Adapted from APASL 2015 recommendations)

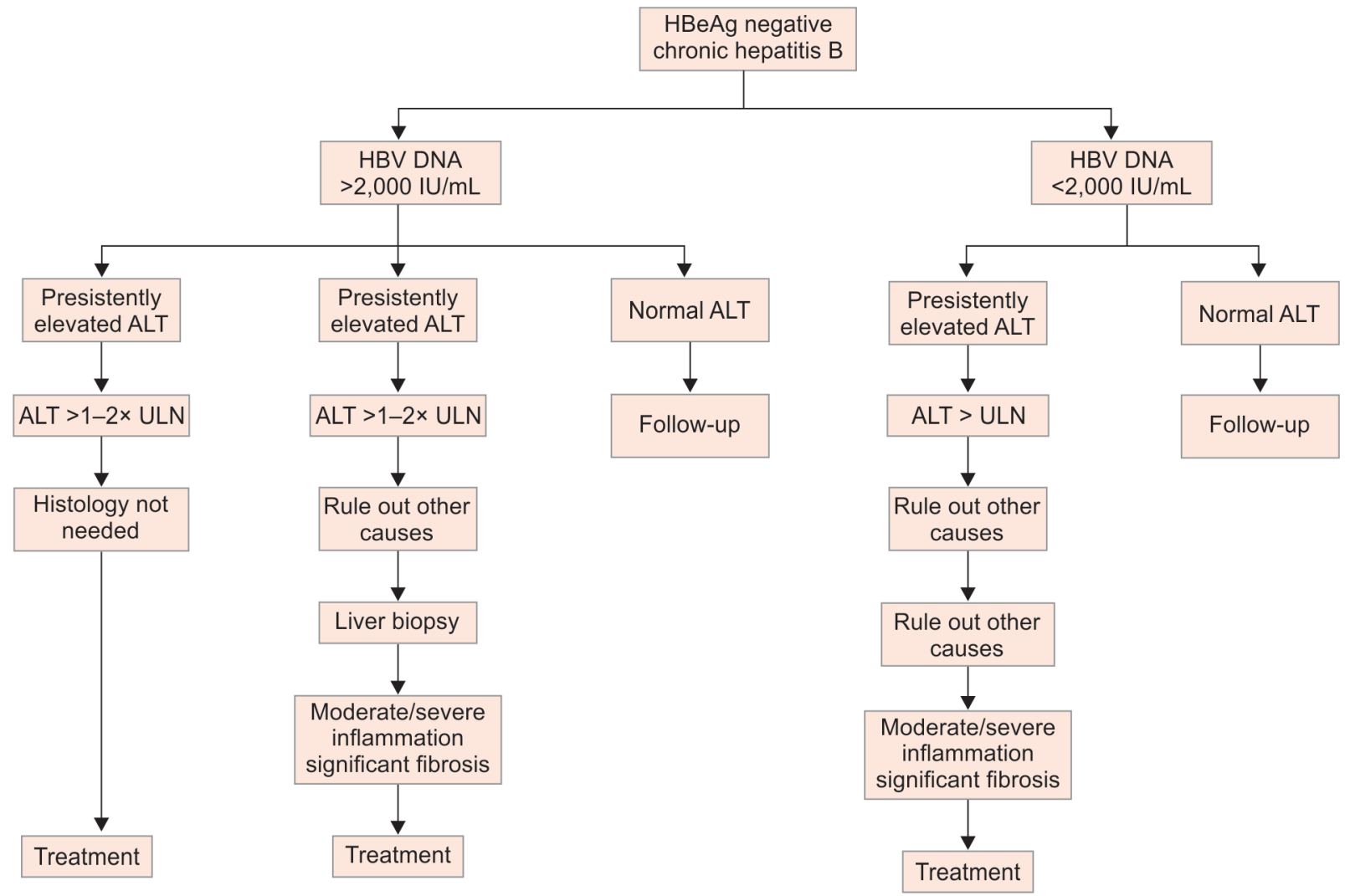


is family H/o HCC or cirrhosis. Treatment is initiated if moderate to severe inflammation or significant fibrosis on liver biopsy is noted.

Inactive carrier or HBeAg-negative infection: These children should be followed up regularly. ALT should regularly be monitored once in 3 months for 1 year; if normal, then every 6-12 months. Liver biopsy is performed if ALT > $2 U L N$, and treatment is initiated if biopsy shows moderate/severe inflammation or HBV DNA > 2000 IU/L.

HBV-related cirrhosis: Those with cirrhosis either compensated or decompensated should be given antivirals irrespective of the level of serum transaminases and HBV DNA. Decompensated cirrhosis patients should be referred for liver transplantation.

HBV-related HCC: Children with HCC should be referred for tumor resection, if feasible, or liver transplantation. If these are not possible, transarterial chemoembolization (TACE) or transarterial radioembolization (TARE) may be attempted.

\section{Perinatal HBV Infection}

Either vertical or horizontal transmission from mother to infant is an important mode of viral spread. The incidence of HBsAg positivity in pregnant women in India is $0.9-1.1 \%$. Most of the transmissions occur during the perinatal period at the time of delivery from the placental blood and cervical secretions, though prenatal and placental transmission may occur in few pregnancies.

Diagnosis: Mother is $\mathrm{HBsAg}$ positive, $\mathrm{HBeAg}$ positive or negative with variable HBV DNA levels.

Therapy: Antiviral therapy is recommended to decrease the viral load and to decrease the mother-to-child transmission. Tenofovir is given during the antenatal period in the last trimester from 26 to 28 weeks and continued for 12 weeks after delivery. Mothers with a high viral load of more than $10^{7}$ copies $/ \mathrm{mL}$, or those with sibling with previous HBV infection and $>10^{6}$ copies $/ \mathrm{mL}$ are candidates for treatment. Babies born to these mothers are administered hepatitis $B$ immunoglobulin ( $\mathrm{HBIG}$ ) along with hepatitis $B$ vaccine within 6 hours of birth.

\section{Clinical Spectrum of HCV Infection}

The spectrum of HCV infection is similar to HBV infection. Since the duration of HCV to progress to chronic liver disease takes more than two decades, most of the problems do not manifest in the pediatric age group and there is some controversy regarding the initiation of treatment in children with HCV infection. However, as there is a 26-fold increase in the risk of liver-related death associated with $\mathrm{CHC}$ acquired in childhood, it is necessary to treat a subset of children.

\section{Acute Hepatitis C (AHC)}

This is not very common in children, but may occur in adolescents using IV drugs with infected needles or following blood transfusion with HCV-positive blood.

Diagnosis: Anti-HCV positive and HCV RNA positive.

Therapy: Since spontaneous resolution is high, treatment is given only for those who continue to be HCV RNA positive 12 weeks after the exposure.

\section{Chronic Hepatitis $\mathrm{C}(\mathrm{CHC})$}

A child is considered to have HCV infection only when there is documentation of HCV RNA in blood. Isolated anti-HCV positivity is not significant. When there is evidence of chronic HCV infection (HCV RNA positive) $>6 \mathrm{~m}$ with ongoing liver injury, the child is said to have chronic hepatitis $C$. All children more than 3 years of age with chronic hepatitis $C$ should be treated. Factors which increase the severity of $\mathrm{CHC}$ are obesity, congenital anemia requiring frequent blood transfusions, survivors of childhood cancer, coinfection with HIV or HBV, and high-risk behaviors in adolescents such as intravenous drug usage and alcohol abuse.

\section{Diagnosis}

HCV RNA positive, elevated serum transaminases.

\section{Therapy}

The existing therapy with PEGylated IFN and ribavirin is associated with several side effects. ${ }^{17}$ The combination of sofosbuvir and ledipasvir has been approved for genotypes 1 and 4 for 12 weeks in treatment-naive patients and 24 weeks in treatment-experienced and cirrhosis patients. The end point of therapy is undetectable HCV RNA in blood by 12 weeks or 24 weeks. The combination therapy has shown $>95 \%$ sustained viral response at 12 weeks (SVR 12) after the end of DAAs treatment. ${ }^{12}$ Those with GT 2 and GT 3 should receive sofosbuvir and ribavirin. Liver transplant is the definitive treatment for those with acute liver failure and decompensated chronic liver disease not responding to antiviral therapy. The algorithmic approach to HCV is shown in Flowchart 4.

\section{Perinatal Transmission of HCV}

The risk of HCV transmission to the neonate mainly depends on the maternal viral load and HIV positivity. Since HCV antibody passively transferred across the placenta persists in the infant till 18 months of age, this test should not be used as a screening test in the newborn or indiscriminately in infancy. HCV antibody should ideally be done after 18 months of age and, if positive, confirmed by HCV RNA. An earlier diagnosis of HCV perinatal transmission may be required either because of parental anxiety regarding the viral status of her baby or because the treating pediatrician is concerned that the infant may be lost to follow-up. In these situations a single test of HCV RNA may be done at the minimal age of 2 months. Irrespective of whether the test result is negative or positive, HCV RNA should be repeated after the age of 1 year, preferable around 18 months

Flowchart 4: Algorithmic approach to management of HCV in children

Suspected HCV infection/incidentally detected anti-HCV

Obtain history, perform clinical exam, look for extrahepatic manifestations

Check HCV RNA PCR

Do CBC, LFT, RFT, INR, viral serology, USG abdomen, fibroscan

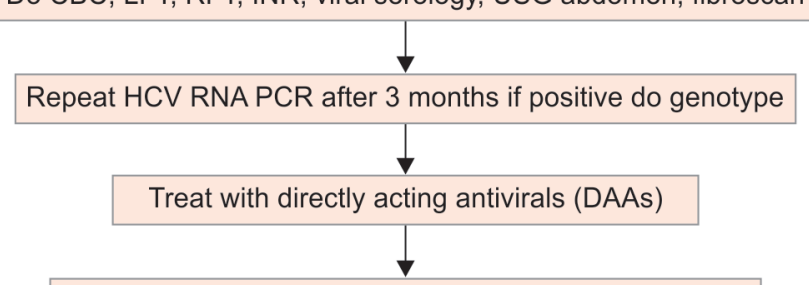

Repeat HCV RNA PCR 12 weeks after completion of treatment with DAAs for confirmation of cure 
Flowchart 5: Algorithm for testing HCV in newborns born to chronic hepatitis C mothers

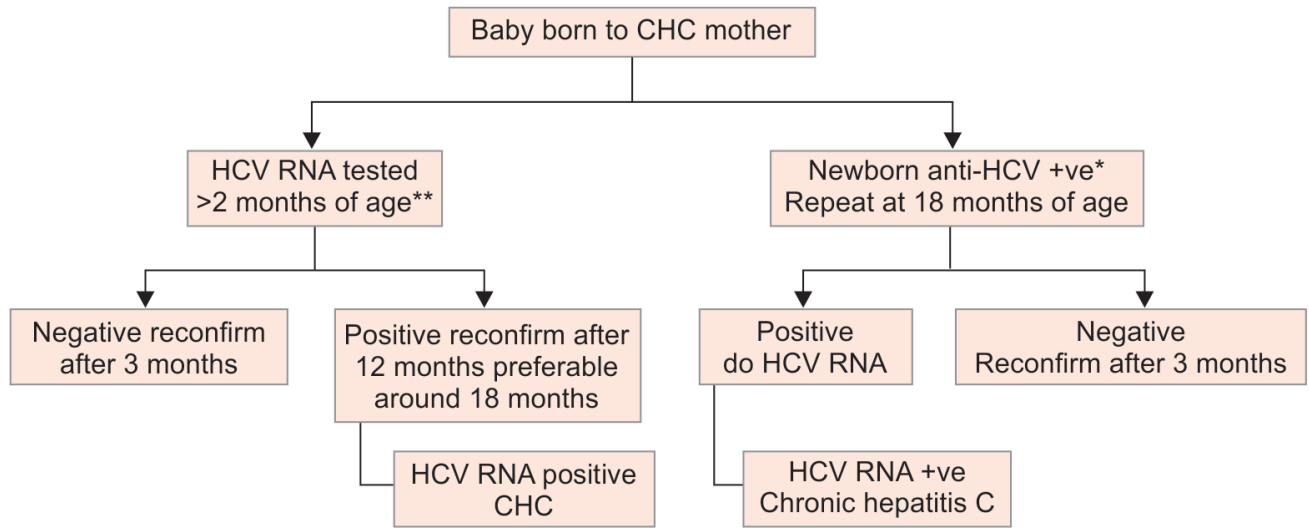

to diagnose chronic hepatitis $C{ }^{18}$ The approach to babies born to HCV-positive mothers is shown in Flowchart 5.

\section{Prevention of HBV and HCV Infections}

Since both the viruses spread through the parenteral route, screening of blood, avoiding unnecessary needle pricks, tattooing and sharing needles among intravenous drug users will decrease the spread of infection.

Maternal screening for HBV and antiviral therapy for mothers with high viral load during the last trimester followed by active and passive immunization of the newborn baby should be done. The neonate born to HBsAg-positive mother is given HBIG 100-200 IU intramuscularly along with hepatitis $B$ vaccine $10 \mu \mathrm{g}$ as zero dose within 6 hours of birth. The complete recommended schedule for $\mathrm{HBV}$ is at 0,1 , and 6 months. Universal immunization against HBV has been included in our national immunization program. The vaccines for hepatitis $C$ virus are also in the pipeline. All children with liver disease should receive vaccines against hepatitis $A$ and $B$.

\section{References}

1. https://www.who.int/news-room/fact-sheets/detail/hepatitis-b.

2. Batham A, Narula D, Toteja T, et al. Systematic review and metaanalysis of prevalence of hepatitis B in india. Indian Pediatr 2007;44(9):663-674.

3. Petruzziello A, Marigliano S, Loquercio G, et al. Global epidemiology of hepatitis $C$ virus infection: an up-date of the distribution and circulation of hepatitis C virus genotypes. World J Gastroenterol 2016;22(34):7824-7840. DOI: 10.3748/wjg.v22.i34.7824.

4. Sievert W, Altraif I, Razavi HA. A systematic review of hepatitis C virus epidemiology in Asia, Australia and Egypt. Liver Int 2011;31(Suppl 2):61-80. DOI: 10.1111/j.1478-3231.2011.02540.x.

5. Squires JE, Balistreri WF. Hepatitis $C$ virus infection in children and adolescents. Hepatol Commun 2017;1(2):87-98. DOI: 10.1002/ hep4.1028.

6. Sood A, Suryaprasad A, Trickey A, et al. The burden of hepatitis C virus infection in Punjab, india: a population-based serosurvey. PLoS One 2018;13(7):e0200461.

7. Xu DZ, Yan YP, Choi BC, et al. Risk factors and mechanism of transplacental transmission of hepatitis B virus: a case-control study. J Med Virol 2002;67(1):20-26. DOI: 10.1002/jmv.2187.

8. Chang $\mathrm{MH}$. Natural history of hepatitis B infection in children. J Gastroenterol Hepatol 2000;15:E11-E19. DOI: 10.1046/j.14401746.2000.02096.x.

9. Sokal EM, Paganelli M, Wirth S, et al. European society of pediatric gastroenterology, hepatology and nutrition. Management of chronic hepatitis B in childhood: ESPGHAN clinical practice guidelines: consensus of an expert panel on behalf of the european society of pediatric gastroenterology, hepatology and nutrition. J Hepatol 2013;59(4):814-829. DOI: 10.1016/j.jhep.2013.05.016.

10. Karnsakul W, Schwarz KB. Hepatitis B and C. Pediatr Clin North Am 2017;64(3):641-658. DOI: 10.1016/j.pcl.2017.01.007.

11. Trifan A, Stanciu C. Checkmate to liver biopsy in chronic hepatitis C? World J Gastroenterol 2012;18(39):5514-5520. DOI: 10.3748/wjg.v18. i39.5514.

12. Indolfi G, Thorne C, El Sayed MH, et al. The challenge of treating children with hepatitis C virus infection. J Pediatr Gastroenterol Nutr 2017;64(6):851-854. DOI: 10.1097/MPG.0000000000001589.

13. Balistreri WF, Murray KF, Rosenthal P, et al. The safety and effectiveness of ledipasvir-sofosbuvir in adolescents 12-17 years old with hepatitis C virus genotype 1 infection. Hepatology 2017;66(2):371-378. DOI: 10.1002/hep.28995.

14. Terrault NA, Lok ASF, McMahon BJ, et al. Update on prevention, diagnosis, and treatment of chronic hepatitis B: AASLD 2018 hepatitis B guidance. Hepatology 2018;67(4):1560-1599. DOI: 10.1002/ hep. 29800.

15. European Association for the Study of the Liver. EASL 2017 clinical Practice guidelines on the management of hepatitis $B$ virus infection. J Hepatol 2017;67(2):370-398. DOI: 10.1016/j.jhep.2017.03.021.

16. Sarin SK, Kumar M, Lau GK, et al. Asian-pacific clinical practice guidelines on the management of hepatitis B: a 2015 update. Hepatol Int 2016;10(1):1-98. DOI: 10.1007/s12072-015-9675-4.

17. CHT Yang, Yoo ER, Ahmed A. The role of direct-acting antivirals in the treatment of children with chronic hepatitis C. J Clin Transl Hepatol 2017;5(1):59-66.

18. Ghany MG, Morgan AA, SLD-IDSA Hepatitis C Guidance Panel. Hepatitis $C$ guidance 2019 update american association for the study of liver diseases-infectious diseases society of America recommendations for testing, managing and treating hepatitis $C$ virus infection. Hepatology 2020;71:686-721. DOI: 10.1002/hep.31060. 